\title{
PERANCANGAN DAN IMPLEMENTASI SISTEM INFORMASI BEBAN KERJADOSEN BERBASIS WEB (STUDI KASUS : UNIVERSITAS DHYANA PURA BALI )
}

\author{
Ni Kadek Ayu Fitriandayani ${ }^{1)}$ Made Agung Raharja $^{2)}$ Christian Tonyjanto $^{3)}$ \\ Program Studi Sistem Informasi ${ }^{1)}$ 3) \\ Program Studi Teknik Informatika ${ }^{2)}$ \\ Fakultas Ilmu Kesehatan Sains dan Teknologi, Universitas Dhyana Pura, badung, Bali 1) 2) 3) \\ fitri08101995@gmail.com ${ }^{1)}$ agungraharja@undhirabali.ac.id ${ }^{2)}$ \\ christiantonyjanto@undhirabali.ac.id ${ }^{3)}$
}

\begin{abstract}
Along with technological developments that are increasingly progressing progress of technology today has an impact in improving the effectiveness and efficiency in doing every job. Usefulness of the computer has a lot to help facilitate the work of humans so the existence of this computer is needed. Both individuals, institutions, and governments take various efforts to take advantage of this information technology development. Even in education in Indonesia, especially college.

Each college has a Tri Dharma activity of universities undertaken by lecturers covering 4 areas, namely: education and teaching, research, community service, support set by the leadership of the university. Therefore, the lecturer's burden must be proportionally distributed and measured by utilizing the development of information technology. One of them is a Web-Based Lecturer Information System (BKD) that can help the leader in knowing the lecturer's workload information that is borne and helps the leader in knowing the workload information that is borne by each lecturer.
\end{abstract}

Keyword : Tri Dharma, Information System, Web-Based Lecturer Information System (BKD)

\begin{abstract}
ABSTRAK
Seiring dengan perkembangan teknologi yang semakin hari semakin berkembang kemajuan dari teknologi saat ini memiliki dampak dalam meningkatkan efektifitas dan keefisienan dalam melakukan setiap pekerjaan. Kegunaan komputer telah banyak membantu memudahkan kerja dari manusia sehingga keberadaan komputer ini sangat dibutuhkan. Baik individu, institusi, maupun pemerintah ikut melakukan berbagai upaya untuk memanfaatkan perkembangan teknologi informasi ini. Bahkan dalam dunia pendidikan di Indonesia, khususnya perguruan tinggi.

Setiap perguruan tinggi memiliki kegiatan tri dharma perguruan tinggi yang dilakukan oleh dosen meliputi 4 bidang, yaitu : bidang pendidikan dan pengajaran, penelitian, pengabdian kepada masyarakat, penunjang yang ditetapkan oleh pimpinan universitas. Oleh karena itu beban dosen harus terdistribusi secara proporsional dan terukur dengan memanfaatkan perkembangan teknologi informasi. Salah satunya adalah Sistem Informasi Beban Kerja Dosen (BKD) berbasis web yang dapat membantu pimpinan dalam mengetahui informasi beban kerja dosen yang ditanggung dan membantu pimpinan dalam mengetahui informasi beban kerja yang ditanggung setiap dosen.
\end{abstract}

Kata Kunci : Sistem Informasi, Beban Kerja Dosen (BKD), Tri Dharma

\section{PENDAHULUAN}

Dosen adalah salah satu komponen penting dalam sistem pendidikan di perguruan tinggi. Sebagaimana diamanatkan dalam UU Nomor 14 Tahun 2005 tentang
Guru dan Dosen, dosen dinyatakan sebagai pendidik profesional dan ilmuwan dengan tugas utama menstransformasikan, mengembangkan, dan menyebarluaskan 
ilmu pengetahuan, teknologi, dan seni melalui pendidikan, penelitian, dan pengabdian kepada masyarakat.

Tugas utama dosen adalah melaksanakan Tri Dharma perguruan tinggi dengan beban kerja paling sedikit sepadan dengan 12 (dua belas) sks dan paling banyak 16 (enam belas) sks pada setiap semester sesuai dengan kualifikasi akademik. Untuk menjamin pelaksanaan tugas dosen berjalan sesuai dengan kriteria yang ditetapkan dalam peraturan perundang - undangan maka dari itu pelaksanaan tugas dosen tersebut perlu dievaluasi setiap periode waktu yang ditentukan.

Universitas Dhyana Pura merupakan salah satu universitas yang diresmikan pada tahun 2011, yang pada awalnya masih berupa Sekolah Ilmu Tinggi Manajemen. Universitas Dhyana Pura yang terletak di Jln. Raya Padang Luwih Dalung ini, memiliki sekitar 184 orang tenaga dosen pengajar. Dengan jumlah dosen tersebut maka evaluasi kinerja dosen sangat penting dilakukan untuk menilai akuntabilitas kinerja dosen dan meningkatkan profesionalisme dosen dalam melaksanakan tugasnya.

Saat ini pengumpulan data dari evaluasi beban kerja dosen yang ada di Universitas Dhyana Pura masih menggunakan cara manual berbasis dekstop. Cara ini dirasakan tidak efisien dari segi waktu, tenaga, dan penyimpanan berkas BKD yang ada. Karena penulisan BKD yang dilakukan secara berulang - ulang setiap tahun membuat penyimpanan berkas yang ada membutuhkan kapasitas penyimpanan yang lebih besar. Selain itu susahnya memasukkan data melalui sistem informasi berbasis dekstop yang telah disediakan karena masih dalam bentuk Microsoft Access.

Oleh karena itu dibutuhkan sistem informasi yang dapat membantu dan mempermudah proses penulisan BKD, sehingga tidak perlu dilakukan penulisan berulang - ulang setiap tahunnya. Sistem informasi berbasis web memiliki tampilan yang lebih dinamis dan lebih mudah digunakan, selain itu kapasitas yang dimiliki lebih besar dari aplikasi berbasis dekstop.

\section{TINJAUAN PUSTAKA}

\section{Pengertian Beban Kerja Dosen}

Sesuai dengan yang diamanatkan

dalam UU Nomor 14 Tahun 2005 tentang

Guru dan Dosen, dosen dinyatakan sebagai pendidik profesional dan ilmuwan dengan tugas utama menstransformasikan, mengembangkan, dan menyebarluaskan ilmu pengetahuan, teknologi, dan seni melalui pendidikan, penelitian, dan pengabdian kepada masyarakat (Bab 1 Pasal 1 ayat 2). Tugas utama dosen adalah melaksanakan Tri Dharma perguruan tinggi dengan beban kerja paling sedikit sepadan dengan 12 (dua belas) sks dan paling banyak 16 (enam belas) sks pada setiap semester sesuai dengan kualifikasi akademiknya.

Evaluasi tugas utama dosen bertujuan untuk meningkatkan profesionalisme dosen dalam melaksanakan tugas, meningkatkan proses dan hasil pendidikan, menilai akuntabilitas kinerja dosen di perguruan tinggi dan mempercepat terwujudnya tujuan pendidikan nasional.

\section{Pengertian Sistem Informasi}

Sistem informasi merupakan gabungan dari perangkat lunak (software), perangkat keras (hardware), infrastruktur, dan Sumber Daya Manusia (SDM) yang saling berkaitan untuk menciptakan sebuah sistem yang dapat mengolah data menjadi informasi yang bermanfaat.

\section{Basis Data}

Basis data merupakan kumpulan data yang terhubung dan disimpan secara bersamaan tanpa kerangkapan data. Data disimpan dan dapat digunakan oleh satu atau lebih program aplikasi secara optimal tanpa mengalami ketergantungan dengan program yang menggunakannya.

\section{Flowchart}

Bagan alir program (program flowchart) merupakan bagan alir yang mirip dengan bagan alir sistem, yaitu untuk menggambarkan prosedur di dalam sistem.

\section{Data Flow Diagram (DFD)}

Data Flow Diagram (DFD) adalah diagram yang menggunakan notasi simbol untuk menggambarkan arus data sistem.

\section{Entity Relationship Diagram ( ERD )}

Entity Relationship Diagram (ERD) adalah diagram yang menggambarkan keterkaitan antar tabel beserta dengan field field di dalamnya pada suatu database sistem. 


\section{Metode Waterfall}

Metode ini adalah sebuah metode yang tepat untuk membangun sebuah perangkat lunak yang tidak terlalu besar dan sumber daya manusia yang terlibat dalam jumlah yang terbatas. Metode ini menekankan pada sebuah keterurutan dalam proses pengembangan perangkat lunak.

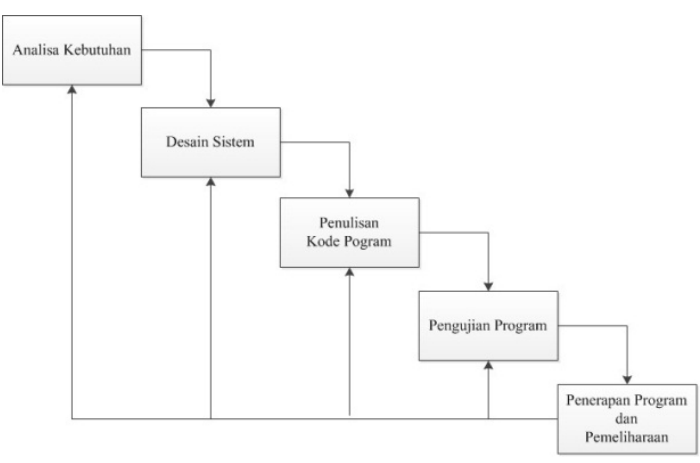

Gambar 1. Metode Waterfall

\section{METODOLOGI PENELITIAN \\ Metode Pengumpulan Data}

Adapun jenis pengumpulan data yang digunakan dalam penelitian sebagai berikut :

1. Wawancara ( Interview )

2. Pengamatan (Observasi)

3. Studi Literatur

\section{Metode Analisis dan Perancangan Sistem}

Adapun metode yang digunakan adalah memakai metode waterfall. Metode ini adalah metode yang mengusulkan sebuah pendekatan kepada perangkat lunak yang sistematis mulai dari tingkat analisis kebutuhan, perancangan sistem, implementasi, pengujian, dan pemeliharaan.

\section{Analisis Sistem}

Analisis

$$
\text { bertujuan untuk }
$$

mengidentifikasi

permasalahan

permasalahan yang terdapat pada sistem serta menentukan kebutuhan dari sistem yang akan dibangun.

\section{Analisis Masalah}

Berdasarkan hasil observasi, para dosen sering mengeluhkan susahnya untuk memasukkan data evaluasi beban kerja dosen. Sistem berbasis dekstop yang digunakan memiliki tampilan yang kurang menarik dan dinamis sehingga penulisan BKD yang dilakukan menjadi kurang efisien dan harus dilakukan secara berulang - ulang. Sehingga dibutuhkan sistem informasi yang memudahkan untuk pengelolaan data evaluasi beban kerja dosen tersebut.

\section{Analisis Kebutuhan}

Analisis kebutuhan menjelaskan kebutuhan, yang diperlukan sistem agar dapat berjalan dengan baik. Adapun kebutuhan sistem yang diperlukan yaitu :

1. Menyimpan data evaluasi beban kerja dosen yang telah dimasukkan.

2. Menampilkan data evaluasi beban kerja dosen dalam bentuk sebuah laporan.

3. Mencetak laporan beban kerja dosen yang telah ditampilkan ke dalam bentuk hardcopy.

4. Tampilan yang lebih menarik dan dinamis dengan sistem berbasis web.

Adapun kebutuhan lain untuk menjalankan aplikasi ini meliputi kebutuhan perangkat lunak dan kebutuhan perangkat keras,yaitu :

1. Kebutuhan Perangkat Lunak

Adapun perangkat lunak yang dibutuhkan untuk membangun sistem informasi beban kerja dosen antara lain :
a. Sistem Operasi Windows 7 Profesional
b. Xampp 3.2.1
c. Bootstrap
d. Jquery
e. Google Chrome
f. Macromedia Dreamweaver CS 8

2. Kebutuhan Perangkat Keras

Perangkat keras yang digunakan untuk mengembangkan sistem ini adalah sebagai berikut :

a. Laptop Acer $4738 \mathrm{z}$ series

b. Processor Intel Pentium

c. RAM 1 GB Harddisk 250 GB

\section{Perancangan Sistem}

Setelah dilakukan analisis dari sistem informasi BKD yang akan dikembangkan, maka langkah selanjutnya adalah membuat desain atau rancangan sistem. Untuk membantu dalam perancangan sistem dibutuhkan alat - alat bantu yang 
berupa suatu gambar, diagram, atau grafik. Pada metodologi kali ini penulis menggunakan alat - alat pengembangan sistem yang terstruktur diantaranya :

\section{Flowchart Sistem Informasi BKD (beban kerja dosen)}

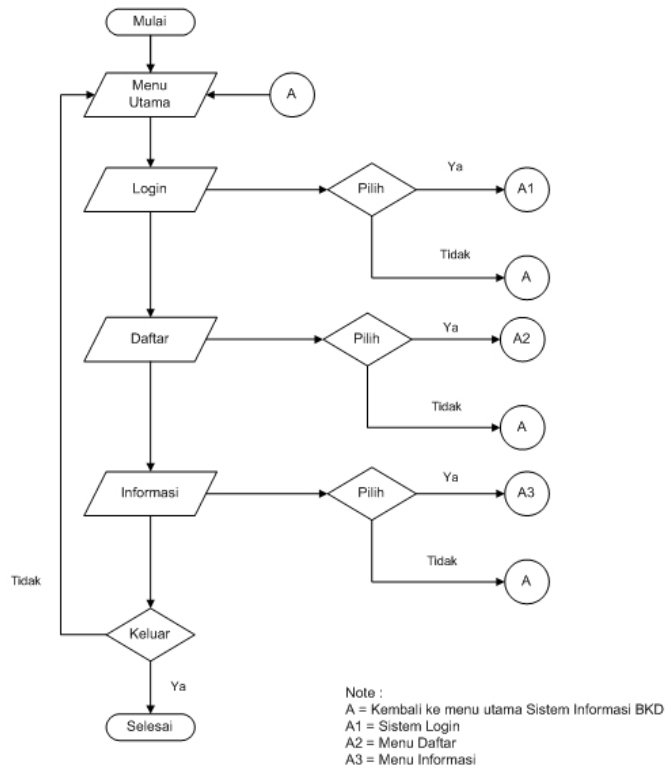

\section{Gambar 2. Flowchart Menu Tampilan Awal Sistem Informasi BKD}

Pada tampilan menu utama ini ada beberapa menu yang ditampilkan di dalamnya yaitu, menu Login, menu Daftar, dan menu Informasi. Untuk masuk ke dalam sistem, user dapat masuk melalui menu Login. Kemudian apabila belum memiliki username dan password untuk user dosen dapat masuk ke menu Daftar. Apabila tidak masuk ke menu informasi dapat memilih menu keluar atau kembali ke tampilan awal web.

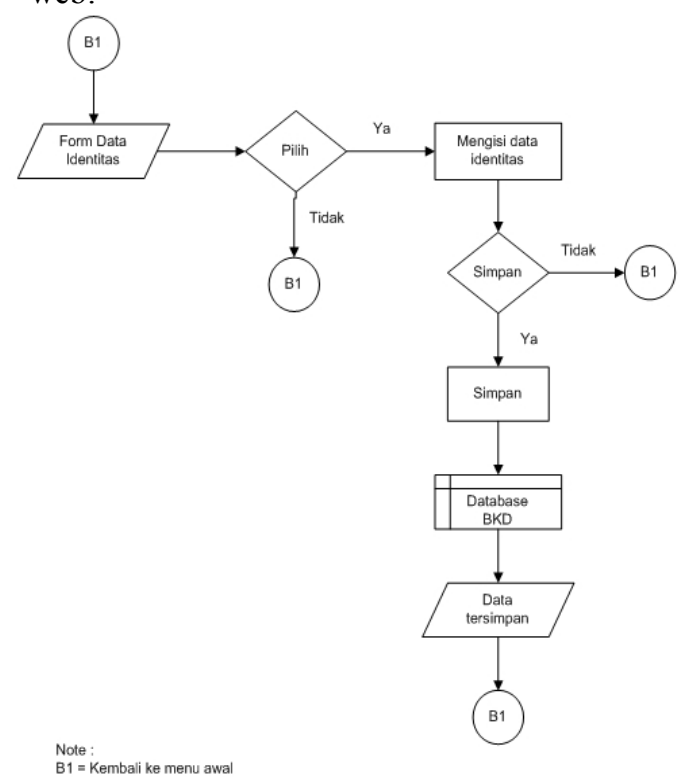

\section{Gambar 3. Flowchart Menu Identitas Dosen}

Pada gambar 3. menjelaskan tentang proses memasukkan data identitas dosen pada form identitas dosen. Setelah mengisi data maka data akan disimpan kedalam database BKD, namun apabila data tidak disimpan maka proses akan kembali ke menu awal identitas dosen.



Gambar 4. Flowchart Menu Kegiatan

Pada gambar 4. menjelaskan tentang proses yang ada pada menu kegiatan dosen. Dimulai dari memilih pilihan tambahkan untuk menambahkan data kegiatan dosen. Setelah mengisi form kegiatan dosen maka data akan disimpan ke dalam database $\mathrm{BKD}$, apabila data tidak disimpan maka proses akan kembali ke tampilan awal menu kegiatan dosen. Kemudian pada pilihan edit dimulai dari memilih data yang akan di ubah lalu pilih pilihan edit, setelah data di dalam form diubah maka data akan disimpan kembali ke database BKD apabila tidak maka akan kembali ke tampilan awal. Untuk pilihan hapus, setelah data dipilih kemudian pilih 
pilihan hapus kemudian data akan terhapus dari tabel.



Gambar 5. Flowchart Menu Cetak

Pada gambar 3.7 menjelaskan tentang proses menampilkan dan mencetak laporan beban kerja dosen. Dimulai dari memilih cover apabila ingin untuk menampilkan bentuk cover laporan kemudian memilih laporan BKD apabila ingin menampilkan laporan BKD ke dalam bentuk pdf. Lalu dapat menggunakan pilihan cetak untuk mencetak laporan BKD ke dalam sebuah dokumen.

Context Diagram Sistem Informasi BKD (beban kerja dosen)

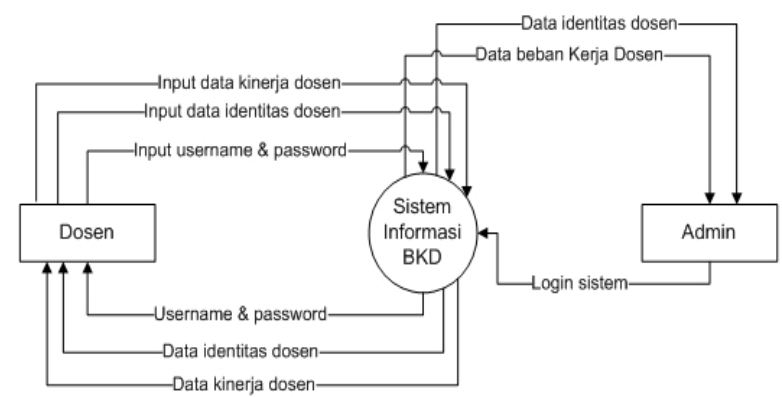

Gambar 6. Context Diagram Sistem Informasi BKD

Pada gambar 6. dijelaskan bahwa kesatuan luar pada Sistem Informasi Beban Kerja Dosen adalah dosen dan admin. Kemudian arus data yang terdapat pada Sistem Informasi ini yaitu sebagai berikut :

1. Dari Dosen : arus data yang berasal dari entitas dosen menuju Sistem
Informasi BKD adalah data username, data password, data identitas dosen dan data kinerja dosen.

2. Dari Sistem Informasi BKD : arus data yang berasal dari Sistem Informasi BKD menuju entitas dosen adalah data user, data password, data identitas dosen yang telah dimasukkan dan data kinerja dosen.

3. Dari Admin : arus data yang berasal dari entitas admin menuju Sistem Informasi BKD adalah data login sistem.

4. Dari Sistem Informasi BKD : arus data yang berasal dari Sistem Informasi menuju entitas admin adalah data identitas dosen dan data beban kerja dosen.

Data Flow Diagram Sistem Informasi BKD (beban kerja dosen)

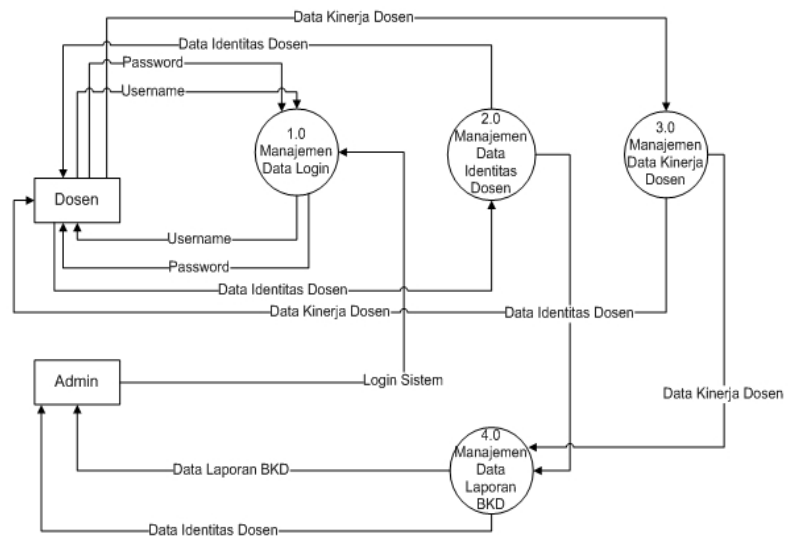

\section{Gambar 7. DFD level 0 Sistem Informasi} BKD

Pada gambar 3.14 menjelaskan tentang DFD level 0 mengenai proses proses yang ada pada konteks diagram. Proses - proses tersebut yaitu manajemen data login, manajemen data identitas dosen, manajemen data kinerja dosen, dan manajemen data laporan beban kerja dosen (BKD). Di dalam proses tersebut kembali dipaparkan alur data pada tiap entitas ke proses dan dari proses ke entitas. Alur data tersebut yaitu :

1. Dari entitas dosen alur data menuju proses manajemen data login adalah username dan password.

2. Dari entitas dosen alur data menuju proses manajemen data identitas dosen adalah data identitas dosen.

3. Dari entitas dosen alur data menuju proses manajemen data kinerja dosen adalah data kinerja dosen. 
4. Dari proses manajemen data login alur data menuju entitas dosen adalah username dan password.

5. Dari proses manajemen data identitas dosen alur data menuju entitas dosen adalah data identitas dosen.

6. Dari proses manajemen data kinerja dosen alur data menuju entitas dosen adalah data kinerja dosen.

7. Dari proses manajemen data identitas dosen alur data menuju ke proses manajemen data laporan beban kerja dosen (BKD) adalah data identitas dosen.

8. Dari proses manajemen data kinerja dosen alur data menuju ke proses manajemen data laporan beban kerja dosen (BKD) adalah data kinerja dosen.

9. Dari entitas admin alur data menuju proses manajemen data login adalah data login sistem.

10. Dari proses manajemen laporan beban kerja dosen (BKD) alur data menuju entitas admin adalah data identitas dosen dan laporan kinerja dosen.

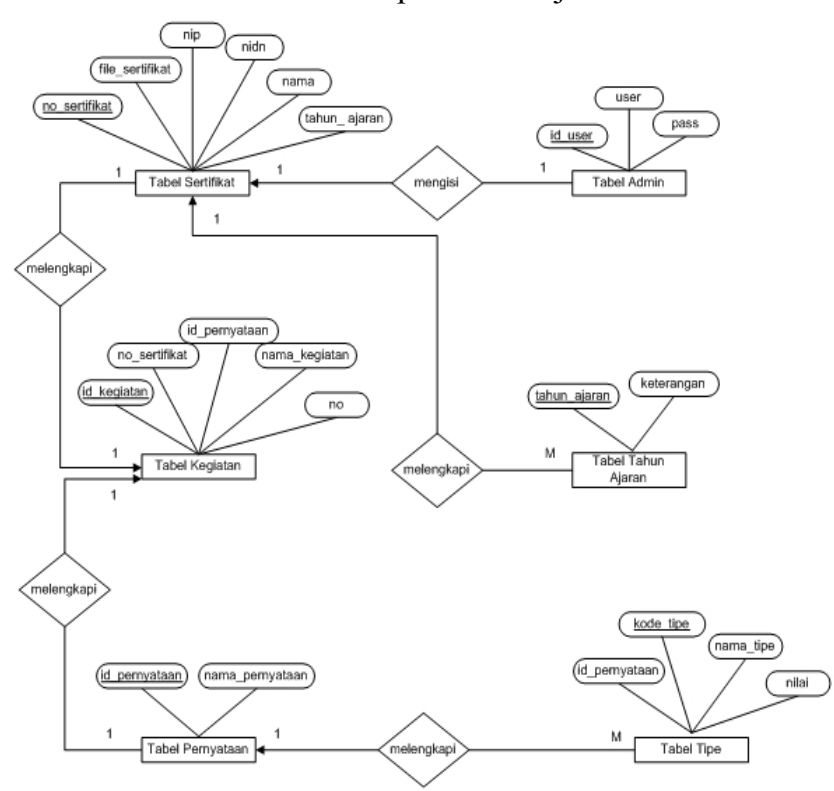

Gambar 8. ERD Sistem Informasi BKD (beban kerja dosen)

Pada gambar 8. menjelaskan tentang Entity Relationship Diagram pada database "bkd". Adapun penjelasannya sebagai berikut, yaitu :

1. Entity Relationship yang terjadi pada Tabel Admin dan Tabel Sertifikat adalah Tabel Admin dapat mengisi Tabel Sertifikat.

2. Entity Relationship yang terjadi pada Tabel Sertifikat dan Tabel Kegiatan adalah Tabel Sertifikat dapat melengkapi Tabel Kegiatan.

3. Entity Relationship yang terjadi pada Tabel Pernyataan dan Tabel Kegiatan adalah Tabel Tipe dapat melengkapi Tabel Kegiatan.

4. Entity Relationship yang terjadi pada Tabel Pernyataan dan Tabel Tipe adalah Tabel Pernyataan dapat melengkapi Tabel Tipe.

5. Entity Relationship yang terjadi pada Tabel Tahun Ajaran dan Tabel Sertifikat adalah Tabel Ajaran dapat melengkapi Tabel Sertifikat.

\section{HASIL DAN PEMBAHASAN \\ Kebutuhan Sistem}

Sebelum mengimplementasikan dan menjalankan sistem informasi beban kerja dosen ini, dibutuhkan beberapa perangkat lunak dan perangkat keras yang digunakan untuk membangun dan mendesain sistem ini agar dapat berjalan dengan baik.

\section{Perangkat Lunak Pembangunan}

Perangkat Lunak Pembangunan menjelaskan perangkat lunak apa saja yang digunakan untuk membangun sistem informasi BKD berbasis web. Berikut adalah perangkat lunak yang digunakan dalam pembuatan sistem informasi ini adalah sebagai berikut :

1. Xampp

2. Macromedia Dreamweaver 8

3. Notepad ++

4. Google Chrome

\section{Perangkat Keras Pembangunan}

Perangkat Keras Pembangunan menjelaskan perangkat keras apa saja yang digunakan untuk membangun sistem informasi Beban Kerja Dosen berbasis web. Berikut adalah perangkat keras yang digunakan dalam pembuatan sistem informasi ini sebagai berikut :

1. Laptop Acer $4780 \mathrm{z}$ series

2. Mouse

3. RAM 1 GB

4. Harddisk $250 \mathrm{~GB}$

Implementasi dalam Pembuatan Sistem Informasi

Pembuatan sistem informasi ini dimulai dengan menginstall beberapa perangkat lunak yang mendukung seperti Xampp versi 3.2.1 ， Macromedia Dreamweaver 8, Bootstrap, Jquery, dan Notepad ++ . 


\section{Relasi Tabel Sistem Informasi BKD (beban kerja dosen)}



\section{Gambar 9. Relasi Tabel Sistem Informasi BKD (beban kerja dosen)}

\section{Implementasi Antarmuka}

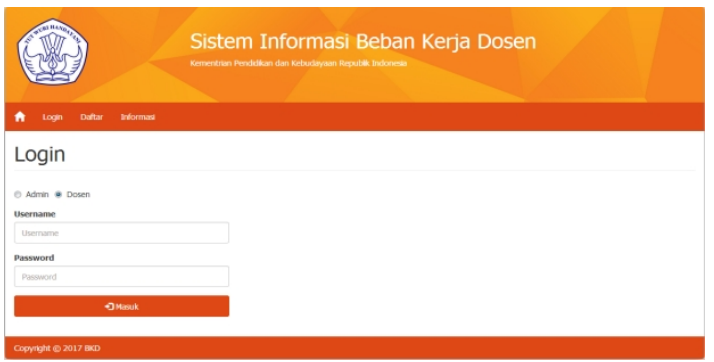

Gambar 10. Tampilan Menu Login

Halaman Menu Login berisi form Login yang harus diisi untuk masuk ke dalam Sistem Informasi Beban Kerja Dosen. Untuk masuk ke dalam sistem user admin dapat memilih admin dan untuk masuk ke dalam sistem user dosen dapat memilih dosen.

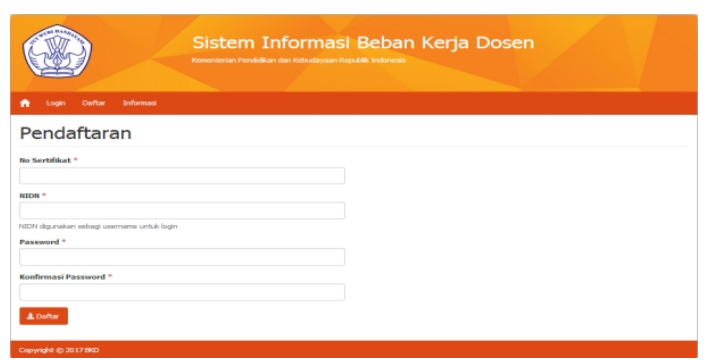

Gambar 11. Tampilan Menu Daftar

Untuk masuk ke dalam Sistem Informasi BKD seorang dosen harus memiliki username dan password. Untuk mendapatkan username dan password, dosen harus melakukan pendaftaran melalui menu daftar. Pada tampilan menu daftar ditampilkan form pendaftaran yang harus diisi oleh dosen.

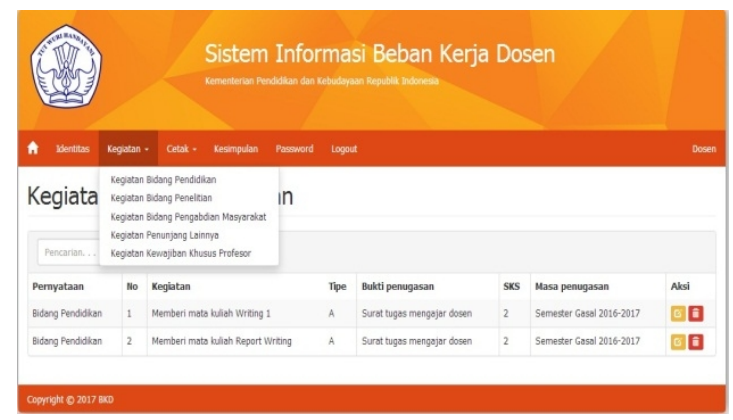

\section{Gambar 12. Tampilan Menu Kegiatan Dosen \\ Untuk membuat laporan beban} kerja dosen, seorang dosen harus mengisi form yang ada pada menu kegiatan. Cara untuk menambahkan kegiatan pada menampilkan form kegiatan adalah pertama, klik menu kegiatan kemudian pilih salah satu jenis kegiatan yang ingin ditampilkan form-nya pada dropown menu yang muncul. Kemudian akan muncul tabel data kegiatan yang telah diisikan sebelumnya, pilih menu tambah yang ada pada tampilan tersebut lalu form kegiatan akan muncul.



\section{Gambar 13. Tampilan Menu Form Tambah Kegiatan}

Tampilan menu form tambah kegiatan akan muncul setelah memilih pilihan tambah pada tabel data kegiatan yang telah ditampilkan. Setelah dosen mengisi form data kegiatan maka data tersebut akan 
ditampilkan ke dalam tampilan tabel pada menu kegiatan dosen.

\section{Pengujian Sistem}

Pengujian sistem merupakan hal terpenting yang bertujuan untuk menguji sistem yang dibuat untuk menemukan kesalahan dan kekurangan sistem. Pengujian sistem yang dilakukan akan memberikan gambaran apakah sistem BKD (Beban Kerja Dosen) berbasis web sudah dapat mengelola data beban kerja dosen pada setiap semester.

\section{Pengujian Teknik Black Box}

Pengujian black box dilakukan dengan mengamati hasil eksekusi sistem melalui data uji dan memeriksa fungsional dari perangkat lunak. Berikut tabel rencana pengujian black box Sistem BKD (beban kerja dosen) :

\begin{tabular}{|c|l|l|l|l|}
\hline No. & $\begin{array}{l}\text { Item Yang } \\
\text { Diujikan }\end{array}$ & \multicolumn{1}{|c|}{ Skenario } & \multicolumn{1}{|c|}{ Hasil } & $\begin{array}{c}\text { Hasil } \\
\text { Pengujian }\end{array}$ \\
\hline 1 & $\begin{array}{l}\text { Halaman } \\
\text { Login }\end{array}$ & $\begin{array}{l}\text { Memilih salah satu user } \\
\text { dengan tombol radio } \\
\text { button, mengisi form } \\
\text { username dan } \\
\text { password }\end{array}$ & $\begin{array}{l}\text { Menampilkan } \\
\text { halaman menu } \\
\text { utama Sistem } \\
\text { Informasi Beban } \\
\text { Kerja Dosen } \\
\text { (BKD) }\end{array}$ & Sesuai \\
\hline
\end{tabular}

Tabel 1. Tabel Pengujian Menu Login

\begin{tabular}{|c|l|l|l|l|}
\hline No. & $\begin{array}{l}\text { Item Yang } \\
\text { Diujikan }\end{array}$ & \multicolumn{1}{|c|}{ Skenario } & \multicolumn{1}{|c|}{ Hasil } & \multicolumn{1}{c|}{$\begin{array}{c}\text { Hasil } \\
\text { Pengujian }\end{array}$} \\
\hline 1 & $\begin{array}{l}\text { Halaman } \\
\text { Daftar }\end{array}$ & $\begin{array}{l}\text { Mengisi form } \\
\text { pendaftaran dengan } \\
\text { No.Sertifikat, NIDN, } \\
\text { Password, Konfirmasi } \\
\text { password, lalu } \\
\text { menekan tombol button } \\
\text { Daftar }\end{array}$ & $\begin{array}{l}\text { Menyimpan data } \\
\text { dan menghasilkan } \\
\text { username dan } \\
\text { login }\end{array}$ & Sesuai \\
\hline
\end{tabular}

Tabel 2. Tabel Pengujian Menu Daftar

\begin{tabular}{|c|l|l|l|l|}
\hline No. & \multicolumn{1}{|c|}{$\begin{array}{c}\text { Item Yang } \\
\text { Diujikan }\end{array}$} & \multicolumn{1}{|c|}{ Skenario } & \multicolumn{1}{|c|}{ Hasil } & $\begin{array}{c}\text { Hasil } \\
\text { Pengujian }\end{array}$ \\
\hline 1 & $\begin{array}{l}\text { Halaman } \\
\text { Kegiatan }\end{array}$ & $\begin{array}{l}\text { Memilih salah satu } \\
\text { bidang kegiatan dari } \\
\text { tombol dropdown }\end{array}$ & $\begin{array}{l}\text { Menampilkan } \\
\text { tabel kegiatan } \\
\text { yang telah } \\
\text { dimasukkan }\end{array}$ & Sesuai \\
\hline 2 & $\begin{array}{l}\text { Button tambah } \\
\text { kegiatan }\end{array}$ & $\begin{array}{l}\text { Menekan tombol } \\
\text { button tambah } \\
\text { kegiatan }\end{array}$ & $\begin{array}{l}\text { Menampilkan } \\
\text { form tambah } \\
\text { kegiatan }\end{array}$ & Sesuai \\
\hline 3 & Button edit & $\begin{array}{l}\text { Menekan tombol } \\
\text { button edit kegiatan }\end{array}$ & $\begin{array}{l}\text { Menampilkan } \\
\text { form ubah } \\
\text { kegiatan }\end{array}$ & Sesuai \\
\hline 4 & Button delete & $\begin{array}{l}\text { Menekan tombol } \\
\text { button delete } \\
\text { kegiatan }\end{array}$ & $\begin{array}{l}\text { Menghapus } \\
\text { kegiatan pada } \\
\text { tabel }\end{array}$ & Sesuai \\
\hline
\end{tabular}

Tabel 3. Tabel Menu Kegiatan

\begin{tabular}{|c|l|l|l|c|}
\hline No. & $\begin{array}{l}\text { Item Yang } \\
\text { Diujikan }\end{array}$ & \multicolumn{1}{|c|}{ Skenario } & \multicolumn{1}{|c|}{ Hasil } & $\begin{array}{c}\text { Hasil } \\
\text { Pengujian }\end{array}$ \\
\hline 1 & $\begin{array}{l}\text { Halaman } \\
\text { Cetak }\end{array}$ & $\begin{array}{l}\text { Menekan tombol } \\
\text { button cetak }\end{array}$ & $\begin{array}{l}\text { Menampilkan pilihan } \\
\text { dropdown untuk } \\
\text { dokumen yang akan } \\
\text { dicetak dan mencetak } \\
\text { dokumen }\end{array}$ & Sesuai \\
\hline
\end{tabular}

Tabel 4. Tabel Pengujian Menu Cetak

\begin{tabular}{|c|l|l|l|l|}
\hline No. & $\begin{array}{l}\text { Item Yang } \\
\text { Diujikan }\end{array}$ & \multicolumn{1}{|c|}{ Skenario } & \multicolumn{1}{|c|}{ Hasil } & $\begin{array}{c}\text { Hasil } \\
\text { Pengujian }\end{array}$ \\
\hline 1 & $\begin{array}{l}\text { Halaman } \\
\text { Sertifikat }\end{array}$ & $\begin{array}{l}\text { Memilih button } \\
\text { sertifikat }\end{array}$ & $\begin{array}{l}\text { Menampilkan } \\
\text { tabel sertifikat }\end{array}$ & Sesuai \\
\hline 2 & $\begin{array}{l}\text { Button } \\
\text { Cetak }\end{array}$ & Menekan button cetak & $\begin{array}{l}\text { Menampilkan } \\
\text { dokumen yang } \\
\text { akan di cetak dan } \\
\text { mencetak } \\
\text { dokumen }\end{array}$ & Sesuai \\
\hline
\end{tabular}

Tabel 5. Tabel Pengujian Menu Sertifikat KESIMPULAN DAN SARAN

Kesimpulan

Berdasarkan perancangan dan implementasi Sistem Informasi Beban Kerja Dosen di Universitas Dhyana Pura, dapat diambil kesimpulan sebagai berikut :

1. Dengan adanya Sistem Informasi Beban Kerja Dosen berbasis web diharapkan dapat mengatasi kesulitan dalam pengelolaan data beban kerja dosen sehingga menjadi lebih mudah dan efisien.

2. Dengan adanya Sistem Informasi Beban Kerja Dosen berbasis web sebagai media pencatatan meminimalkan terjadinya penumpukan data atau kekeliruan data beban kerja dosen yang telah dimasukkan.

\section{Saran}

Berikut adalah beberapa saran yang penulis berikan untuk arah pengembangan selanjutnya terhadap Sistem Informasi Beban Kerja Dosen berbasis web. Adapun saran - saran tersebut sebagai berikut :

1. Diharapkan Sistem Informasi Beban Kerja Dosen berbasis web yang telah dibuat dapat dikembangkan menjadi sistem yang bersifat online karena saat ini sistem yang dibuat masih bersifat offline, dengan dukungan beberapa unit kerja yang mendukung.

2. Diharapkan untuk pengembangan lebih lanjut pada Sistem Informasi Beban Kerja Dosen ini, agar dapat disinkronkan dengan Sistem Beban Kerja Dosen dari Ristek Dikti.

\section{DAFTAR PUSTAKA}

[1] Azhar, Muhammad. 2015. Sistem Informasi Repository Digital Beban Kerja Dosen.

[2] Direktorat Jenderal Pendidikan Tinggi dan Dinas Pendidikan. 2010. Pedoman Kerja Dosen dan Evaluasi Pelaksanaan Tridharma Perguruan Tinggi

[3] Jogiyanto. 2005. Analisis dan Desain Sistem Informasi. Yogyakarta : Andi.

[4] Mahdi, Adnan. 2014. Panduan Penelitian Praktis untuk Menyusun Skripsi, Tesis, \& Desertasi. Bandung : Alfabeta. 
[5] Martin, James. 1975. Computer DataBase Organization. Prentice Hall.

[6] Pratama, A.Eka. 2013. Sistem Informasi dan Implementasinya. Bandung : Informatika Bandung.

[7] R.S, Pressman. 2010. Software Engineering : A Practitioner's Approach. New York : McGraw-Hill.

[8] Raharjo, Budi. 2016. Modul Pemrograman Web (HTML, PHP, \& MySQL) edisi ketiga. Bandung : Modula.

[9] Sutanta, Edhy. 2011. Basis Data dalam Tinjauan Konseptual. Yogyakarta : Andi. 